Sign Systems Studies 46(2/3), 2018, 392-397

\title{
About the (semiotic) limits of the human language: Discussing the case of Pirahã
}

\author{
Ekaterina Velmezova ${ }^{1}$
}

On 21 February 2017, the Institute of Linguistics of the Russian Academy of Sciences in Moscow hosted a conference devoted to the discussion of the book by Daniel L. Everett that had been published in Russian in 2016 under the title Ne spi - krugom zmei! Byt i yazyk indejtsev amazonskih dzhunglej (Don't Sleep, There Are Snakes [Around]: Life and Language [of the Indians] in the Amazonian Jungle $)^{2}$. After the conference, video recordings of all presentations made during the conference were posted at the website of the Institute of Linguistics ${ }^{3}$. This provided an opportunity even without attending the conference to reflect on it in the light of a possibility to understand better the current situation in the humanities, on the one hand, and the relationships between various disciplines (including linguistics and biology) in the historical aspect, in particular in the context of an interest in the problems of semiotics, on the other hand.

Several Russian linguists from different cities took part in the conference - most of the participants were from Moscow, but some scholars came to the conference from St. Petersburg, Irkutsk and Kazan. All papers were presented, and discussions conducted, in Russian. This survey will allow the scholars who do not speak the Russian language to get acquainted with the conference materials in the light of the interdependence of the different disciplines mentioned above, in a historical context.

Already in the "opening remarks" to the conference ("Opening address: Why does the book have such a resonance?”) - which, de facto, were the first report ${ }^{4}$ the then Head of the Institute of Linguistics Vladimir Alpatov stressed that the

\footnotetext{
1 Author's address: Centre for Linguistics and Language Sciences, Anthropole, bureau 4086, University of Lausanne, CH-1015 Lausanne, Switzerland; e-mail: ekaterina.velmezova@unil.ch.

2 Cf. the title of the book Everett 2008.

3 http://iling-ran.ru/main/news/170308_everett.

4 Further in this survey, we shall not necessarily follow the order in which the papers were presented at the conference, instead grouping the presentations around the main problems discussed in them.
} 
translated book could be of interest to specialists in several fields. Discussing it from the position of a historian of linguistics (Alpatov's main professional sphere of interest), the combination of two tendencies can be noted in the work of Everett (as a rule, these tendencies alternate in the history of language sciences, excluding each other). These are: (a) discovery of new, previously unknown linguistic facts, and (b) construction of new theories on their basis. According to Alpatov, one of Everett's main opponents is Noam Chomsky, who turns out to be much closer to structuralism than it is usually assumed - at least if we take into account the thesis, shared by both Chomsky and the structuralists, that linguistic research should not concentrate primarily on connections between language and culture. Languages, according to Everett, are less similar than Chomsky believed (of course, Everett was not the first to express this point of view); and if for Chomsky linguistics is a part of psychology, for Everett (as, for example, also for Edward Sapir), linguistics is a part of anthropology: in his opinion, language is defined by culture and is not a part of the human genome. In Alpatov's view, it is difficult to agree with some theses of Everett's - for example, with his idea that languages "without syntax" are possible: according to the Russian scholar, particular ways of combining lexical units with each other in Pirahã can also be considered as syntax, etc. Some other theses of Everett's, said Alpatov, are difficult both to prove as well as to refute for example, the statement that the absence of recursion in the Pirahã language supposed by Everett can be explained by the very way of life of the Pirahã tribe. Thus, already the first paper delivered at the conference stressed how carefully all kinds of linguistic "sensations" should be treated: any representation of a language to a large extent depends on the chosen models of description.

An interest in the history of linguistics was also manifested in many other presentations. In the paper delivered by the Moscow linguist Anna Dybo and titled "Pirahã and Aranta: Typology of descriptions", a parallel was drawn between Everett's book and another "bomb" which exploded in the language sciences almost eighty years ago - Alf Sommerfelt's research on the Aranta language (Sommerfelt 1938). In this way, the possibility of turning to the history of language sciences for a more cautious attitude towards all kinds of sensations was discussed at the conference once again. Another Moscow linguist, Maksim Krongauz in his paper "The Benjamin Whorf of the 21st century" compared Everett's works with Whorf's research. According to Krongauz, they had the following points in common: neither Whorf nor Everett were professional linguists, but it was supposed they had an exclusive access to a rare, "exotic" language. Their linguistic "discoveries" in many ways presupposed the relativization of the seemingly absolute linguistic universals (such as the existence, in every human language, of recursion, or of the grammatical category of time). Both Whorf and Everett considered languages in 
inseparable connection with the cultures of the respective peoples, and even if a number of conclusions presented by them seemed, or still seem, to be controversial, the descriptions of "exotic" languages they studied provoked heated discussions. It is still too early to predict the possible duration of these discussions in the case of Everett; in the case of Whorf, they lasted for several decades.

In the paper titled "Daniel Everett and linguoculturology", the Moscow linguist Pavel Dronov, editor of the Russian translation of the book who had also translated the monograph together with Igor Mokin and Evgenij Panov, to a large extent dealt with the history of linguistics as well. As he emphasized, objecting to Chomsky in particular (although using the terminology of generativists), Everett insisted on the connection between language and culture, to some extent echoing many linguists of previous generations - for example, Wilhelm von Humboldt, Johann G. Herder, Alexander Potebnya and many others who had written about the dependency of thought on the corresponding languages and cultures, which allowed to put forward the concept of the 'linguistic picture/image of the world'. To support his theses, Dronov also used examples from another work by Everett Language: The Cultural Tool. The topic of connection between languages and cultures was also addressed in the paper "The Pirahã language, the Swadesh list and linguistic universals" delivered by Aleksej Koshelev, head of the Moscow publishing house Yazyki slavyanskoj kul'tury where the book by Everett under discussion had been published. According to Koshelev, the most interesting thing about the Pirahã language is not its particular "exotic" features (lack of numbers, of colour names, etc.), but the combination of many unusual properties. Referring to Lewis H. Morgan's theory of the one common way in the development of humanity, A. Koshelev explained this peculiarity of Pirahã by a particular "level of development" of culture in the society speaking this language.

In several presentations, disagreement with Everett's supposedly sensational conclusions was clearly voiced. According to the Moscow linguist Svetlana Burlak, who delivered the paper "The language of Pirahã and colloquial speech", it is hardly possible to come to all the sensational conclusions which Everett reached in his book, when analysing only a conversational form of languages: if, for example, one relies only on the material of oral Russian speech, also Russian syntax can be presented in a rather unexpected way. Continuing to discuss the question of the objective character of the descriptions of Pirahã presented by Everett, the St. Petersburg linguist Vadim Kasevich started his paper "Minimalism in language and speech" with the thesis that, describing the empirical material, one should, first, have the necessary training (i.e. be a professional linguist), and secondly, know the skills relevant for the work (field research). As to Everett, Kasevich emphasized that he had neither the necessary education nor the required professionalism. In 
this way, the "sensational" nature of the information about Pirahã, obtained thanks to Everett's book, was again set in question on the grounds of several examples for instance, the discovery of tones in Pirahã. Drawing parallels between some features of Pirahã and the peculiarities of the Athabaskan languages in his paper "The tyranny of unfamiliar mind", the Moscow linguist Andrej Kibrik, the present Head of the Institute of Linguistics, came to the conclusion that much of what is described by Everett as an exception to the general, universal rule, in fact, is not so. The researcher also contested Everett's thesis that generative grammar can be called into question because there are (supposedly) no recursive structures in Pirahã. According to Kibrik, on the one hand, there exist recursive structures in the Pirahã language - as it was once again emphasized, Everett does not seem to understand that the written and the oral linguistic modes are fundamentally different; besides, once again the question arises as to what exactly can be called recursion. On the other hand, recursion should not be considered a defining feature of syntax. As the speaker stressed, if one recognizes that (human) language is not equal to syntax, and that recursion is not a distinctive property of the syntactic organization of human language in general, the element of sensation, which at first glance distinguishes the book discussed at the conference, will disappear to a large extent.

An attempt to contest the unique and exotic character of the reflection, in the Pirahã language, of the so-called immediacy-of-experience principle was undertaken in the paper by Aleksandr Kravchenko (Irkutsk) "How exotic is the 'immediacy-of-experience principle' in the Pirahã language?". In the paper entitled "Riau, Pirahã: What's next?" and presented by the linguist Valerij Solov'ev from Kazan, according to himself, a follower of Chomsky (among other things, in 1997 Solov'ev participated in the organization of a major international conference on the 40th anniversary of Chomsky's book Syntactic Structures [Solov'ev 1998]) - it was emphasized that Everett's work under discussion does not refute Chomsky's theories, already because the absence of subordinate constructions does not presuppose the absence of recursion in the language in question. Comparing some data from Everett's book with the data on the Riau Indonesian language, and thereby once again questioning the thesis of the uniqueness of Pirahã, the researcher concluded that the creation of a "universal theory" based on the material of "exotic" languages (Pirahã, Riau, etc.) is very unlikely. Finally, the question of the "fundamental novelty" of the descriptions of the Pirahã language was raised in the paper "Notes on the Pirahã language" by Evgeniya Korovina (Moscow), who pointed out that already before the publication of Everett's works, linguists had had some information about this language at their disposal.

From the point of view of the connections of linguistics and biology with semiotics, in this particular case it would have been interesting to discuss, among 
other things, the problem of the (semiotic) boundary separating human language from other semiotic systems, for instance, the language of animals - in particular, due to their different biological (anatomical) foundations. This question is directly related to the problem of linguistic universals - those traits that are supposedly inherent in any human language (cf. the Saussurian langue), thereby distinguishing the human language from several other semiotic systems, such as the language of animals. If the relations between signs are discussed rather than the types of signs, the question of syntax will inevitably arise. Considering recursion as the basis of syntax and recognizing the absence of recursion in Pirahã, can we speak of this language as an exception to the rule going back to some general semiotic character of all human languages? As the discussion has shown, the question, once again, is rather connected with terminology than with any "sensational" discoveries.

According to Thomas A. Sebeok, in particular, syntax is a singular component of the human language. As it has already been specified, "what he calls syntax, should be better denominated syntactics. [...] The fact that language, a secondary modeling system, incorporates a syntactic component (articulation), as Sebeok says, is singular: this feature is not present in other zoosemiotic systems, although it abounds in endosemiotic systems, such as the genetic code, the immune code, the metabolic code, and the neural code (Sebeok 1991, pp. 57-58)" (Petrilli, Ponzio 2015: 52). Humans' capacity to combine linguistic elements can have a biological basis: a specific structure of the human brain, in comparison with the brain of primates. Understood in this sense, syntax, of course, cannot be reduced to recursion (at least in one of the definitions of the phenomenon of recursion). Therefore, even if we admit the absence of recursive structures in Pirahã (this particularity was among those most often mentioned at the conference), one can hardly speak of any linguistic or semiotic "sensation". Let us specify again: references of many speakers to the history of ideas obviously helped the conference participants draw parallels with the past of the language sciences and thus relativize the seemingly unique case of the "discovery" and descriptions of the "unique" Pirahã language.

\section{References}

Everett, Daniel 2008. Don't Sleep, There Are Snakes: Life and Language in the Amazonian Jungle. New York: Pantheon Books - London: Profile Books.

- 2012. Language: The Cultural Tool. London: Profile Books.

- 2016. Ne spi - krugom zmei! Byt i yazyk indejtsev amazonskih dzhunglej. Moskva: Yazyki slavyanskoj kul'tury. [Не спи - кругом змеи! Быт и язык индейцев амазонских джунглей.] 
Petrilli, Susan; Ponzio, Augusto 2015. Language as primary modeling and natural languages: A biosemiotic perspective. In: Velmezova, Ekaterina; Kull, Kalevi; Cowley, Stephen J. (eds.), Biosemiotic Perspectives on Language and Linguistics. Cham: Springer, 47-76.

Sebeok, Thomas Albert 1991. A Sign is Just a Sign. Bloomington: Indiana University Press.

Solov'ev, Valerij Dmitrievich 1998. Hronika konferencii The 40-th Anniversary of Generativism. [Хроника конферениии The 40-th Anniversary of Generativism.] Voprosy yazykoznaniya 6: 118-119.

Sommerfelt, Alf 1938. La langue et la société. Caractères sociaux d'une langue de type archaïque. Oslo: Aschehoug et Co. 